\title{
Heroes and Villains in Complex Socio-Technical Systems
}

Jonathan Gao and Sidney Dekker

Mailing Address: Safety Science Innovation Lab, Macrossan Building (N16), Griffith University, 170 Kessels Road

Corresponding Author's E-mail: jonathan.gao@griffithuni.edu.au 


\begin{abstract}
Background: The history of efforts to reduce 'human errors' across workplaces and industries suggests that people (or their weaknesses) are seen as a problem to control (Clarke, 2010; Haq, 2013; Levitt, 2014; Reason, 2008; Woods \& Cook, 2002). However, some have proposed that humans can be heroes as they can adapt and compensate for weaknesses within a system and direct it away from potential catastrophes (Reason, 2008). But the existence of heroes would suggest that villains (i.e. humans who cause a disaster) exist as well (Clarke, 2010), and that it might well be the outcome that determines which human becomes which (Baron \& Hershey, 1988).
\end{abstract}

Objective: The purpose of this chapter is to examine if complex socio-technical systems would allow for the existence of heroes and villains, as outcomes in such systems are usually thought to be the product of interactions rather than a single factor (Leveson, 2002).

Structure: The chapter will first examine if the properties of complex systems as suggested by Dekker, Cilliers, and Hofmeyr (2011) would allow for heroes and villains to exist. These include: (a) synthesis and holism, (b) emergence, (c) foreseeability of probabilities, not certainties, (d) timeirreversibility and, (e) perpetual incompleteness and uncertainty of knowledge, before concluding with a discussion of the implications of the (non) existence of heroes and villains in complex systems for the way we conduct investigations when something goes wrong inside of those systems.

Keywords: Complexity, Heroic Recovery, Human Error 


\section{$* 1 \quad$ Introduction}

The history of efforts to reduce "human errors" across workplaces and industries strongly suggest that people (or their weaknesses) are seen as a problem to control, typically via replacing the "faulty" individual or the addition/enforcement of procedures [1-7]. For instance, the National Transportation Safety Board (NTSB) [6] stated in their Most Wanted List of Transportation Safety Improvements that accidents can be reduce if pilots were to comply with procedures.

Such notions are single-factor explanations that condense accounts of failure to individual human action or inaction. An analysis by Holden [2] showed that between 1999 and 2006, 96\% of investigated US aviation accidents had their cause mostly attributed to the flight crew. In $81 \%$ of these accidents, people were the only reported cause. "Crew failure" or similar terms were used to describe $74 \%$ of probable causes while the remaining cases contained language such as "inadequate planning, judgment and airmanship," "inexperience" and "unnecessary and excessive . . inputs.". "Violation" of written guidance was stated as cause or contributing factor in a third of all cases.

However, contemporary research suggests otherwise [8-12]. In their review of 13 studies, Alper and Karsh [8] discovered that procedural violations were due to a myriad of reasons, such as a lack of information, poor system design, and competing goals. This finding is consistent with work done by de Brito [9], whose study revealed that factors such as interruptions or difficulties in locating the correct protocols during an emergency contributed to pilots violating procedures. Such a phenomenon has been observed in other domains as well. For instance, de Saint Maurice et al., [10] found that anaesthetists tend to deviate from procedures when they had unscheduled surgery, or when work demands were high. In other words, present research strongly indicates that the reasons for procedural violations are more complex than intentional non-compliance by humans.

In contrast to the view of humans as a liability, some have advocated for the view of humans as a valuable resource [13-15]. Reason [15] even argues that humans can be heroes as they are able to adapt and compensate for weaknesses within a complex system and hence direct it away from 
potential disasters. However, the existence of heroes would suggest that villains (i.e. humans who cause a disaster) exist as well [16].

Therefore, the purpose of this chapter is to examine if complex socio-technical systems would allow for the existence of heroes and villains within it, as outcomes in such systems are usually thought to be the product of interactions rather than a single factor [17]. Complexity Theory suggests that we see performance as an emergent property, the result of complex interactions and relationships. This stands in sharp contrast with the perspective from Newtonian Science.

\section{*.2 Newtonian Science, Cause and "Human Error"}

Newtonian Science is one of simplicity [18]. The complexity of the world is thought to be superficial and can be broken down into individual components. Each component can then be analysed to determine its role. Such simplistic thinking is often used in investigative and legal reasoning in the aftermath of accidents to find a cause. Newton Science believes that all accidents have a definitive, identifiable cause and a definitive effect, and that cause and effect are symmetrical. In other words, the bigger the effect, the bigger the cause. Identification of a "cause" or "causes" is generally seen as the most important function of an accident investigation. However, this assumes that the physical effects of an accident can be traced back to physical causes. If efforts to determine causeeffect relationships cannot be achieved, then the typical response is to deem the accident analysis method or agency as unworthy[18]. Then Chairman of the NTSB, Jim Hall, raised the spectre of his agency at not being able to find the "faulty" part in TWA 200, which would challenge its entire reputation (p. 119): "What you're dealing with here is much more than an aviation accident... What you have at stake here is the credibility of this agency and the credibility of the government to run an investigation.” [19].

\section{*.3 Complexity Theory}

In contrast with Newtonian Science, Complexity Theory proposes that complex behaviour arises because of the interactions between the components of a system [18]. The properties of a system emerge from these interactions, instead of being contained within individual components. 
External designers are not necessary for a complex system, as new structures can be generated internally. These internally generated structures can adjust in response to changing conditions in the environment. Complexity is a feature of the system, not of components inside of it. The knowledge of each component is limited and local, and no component can possess enough capacity to represent the complexity of the entire system. The behaviour of the system cannot be reduced to the behaviour of the components. Complex systems are held together by local relationships only. Each component is ignorant of the behaviour of the system as a whole, and cannot know the full influences of its actions. Components respond locally to information presented to them, and complexity arises from the huge, multiplied webs of relationships and interactions that result from these local actions. Asymmetry or non-linearity in these relationships means that a tiny change in initial conditions can lead to huge differences later. There are no linear, symmetrical cause-effect relationships like that of Newtonian Science.

This chapter will first examine if key properties of complex systems, namely: (a) synthesis, holism, and emergence, (b) foreseeability of probabilities, not certainties, (c) time-irreversibility and, (d) perpetual incompleteness and uncertainty of knowledge, would each allow for heroes and villains to exist. It will then conclude with a discussion of the implications of the (non) existence of heroes and villains in complex systems for the way investigations are conducted when something goes wrong inside of those systems.

\section{*.4 Synthesis, Holism, and Emergence}

Essentially, the properties of synthesis, holism, and emergence mean that one cannot hope to break down a complex system into its individual components to locate a broken part, unlike the Newtonian belief that such an act is possible [18]. Happenings within a complex system emerge due to the multiple interactions between various components and as such, a holistic view is needed to understand it. Some have proposed that individuals within complex systems are unable to fully understand every process involved in the system's functioning, due to its complexity $[14,20]$. This means that individual effort is unlikely to play a huge role in steering a system both away from and towards disasters, as an individual's lack of understanding means that s/he would be unable to 
deliberately make changes that will have a positive impact throughout the system. In other words, heroes and villains do not exist.

Yet, Rochlin et al., [20] observed that anyone working on an aircraft carrier had the right to stop all flights if they think that such an action would avoid accidents, suggesting that perhaps heroes (and as a consequence, villains) can exist in complex systems. A second example of an individual who was able to steer a complex system away from potential dangers and towards improvements is perhaps Florence Nightingale.

\section{*.4.1 Case Study: Florence Nightingale}

In her lifetime, Florence Nightingale made numerous positive contributions to the British healthcare system and hence is regarded as the founder of modern nursing [21-23]. Her first major set of contributions took place during the Crimean War, when then Secretary of State at War Sidney Herbert requested Florence Nightingale to lead a group of nurses to the battlefield [24,25]. Upon arrival, Florence Nightingale began to tap into her political connections to improve the state of affairs in various hospitals. For instance, she was able to increase the quality of the male nursing orderlies (they were responsible for majority of the work), and secure valuable equipment for her hospitals despite some difficulties.

After the Crimean War, Florence Nightingale returned to England and began an attempt to establish a royal commission for the study of: (a) sanitary conditions, (b) management and organisation of barracks and military hospitals, and (c) administration, training, and organisation of the Army Medical Department [24,26]. Despite some obstacles, her attempt was a success and the formation of the royal commission led to several positive reforms to the British healthcare system.

Furthermore, Florence Nightingale's popularity led to the creation of the Nightingale Fund, used to establish the Nightingale Training School for nurses [27]. Although there were problems with the school (e.g. poor management), it did exert a profound influence in the nursing domain. For example, Lucy Osburn, the founder of modern nursing in Australia, received her training in the Nightingale Training School [28]. Likewise, Linda Richards, who was a prominent figure in 
American nursing (and perhaps Japanese nursing), was heavily influenced by Florence Nightingale's work $[29,30]$.

Besides the above contributions, Florence Nightingale also played a critical role in the conception of the Metropolitan Poor Law Act [31]. Back then, workhouses exist to provide the disabled and the poor a small amount of assistance in terms of food, shelter, warmth, and care [32]. The Metropolitan Poor Law Act led to the setting up of the Metropolitan Asylum District for the separation and healing of those with insanity, fever, or small-pox [31]. Well-built dispensaries and infirmaries were also established for the poor who were afflicted with non-infectious illnesses. Most importantly, the Act led to the launch of the Metropolitan Common Poor Fund which was used to financially support the various programs.

Lastly, Magnello [33] claims that Florence Nightingale was among the first to employ statistics in the analysis of healthcare data, thereby revolutionising the nursing domain and causing a decline in avoidable deaths. For example, Florence Nightingale made use of statistics to convince government officials of the urgent need for sanitary reforms. She also introduced standardised forms which were used in various major London hospitals and parts of Europe to facilitate the collection of medical data.

In summary, Florence Nightingale appears to have played an influential role in steering the healthcare systems of various countries away from disasters and towards improvements. In complex systems, as the truism goes, one actor cannot control much. But they can influence almost everything. This seems to indicate that the efforts of an individual can have enormous repercussions on a complex socio-technical system, meaning heroes and villains can potentially exist in these systems.

\section{*.5 Foreseeability of Probabilities, not Certainties}

According to Newtonian Science, the future of a component can be predicted with absolute certainty if its state at any time was known in complete details [18]. With sufficient knowledge of the initial conditions of a component, and the laws that govern the motion of the component, all subsequent events are foreseeable. In other words, if someone can be shown to have known (or should 
have known) the initial positions and momentum of the components of a system, and the forces acting on these components (which includes both external forces and those determined by the positions of these and other components), then this person could, in principle, have predicted the further evolution of the system with complete certainty and accuracy.

If complete and accurate knowledge is achievable, then harmful outcomes should be predictable [18]. Therefore, it makes sense (at least from a Newtonian Science perspective) to ask why someone failed to predict an accident when it occurs. Were they unaware of the laws governing their part of the universe (i.e. were they incompetent or unknowledgeable)? Or have they failed to plot out the possible effects of their actions? Indeed, legal reasoning follows this feature of the Newtonian model when determining if an individual was negligent (p. 6): "Where there is a duty to exercise care, reasonable care must be taken to avoid acts or omissions which can reasonably be foreseen to be likely to cause harm. If, as a result of a failure to act in this reasonably skilful way, harm is caused, the person whose action caused the harm, is negligent" [34]

In other words, someone can be considered as negligent or villainous if he/she did not avoid actions that could be foreseen to lead to negative effects [18]. Effects that would have been predictable and therefore avoidable if the person had made an effort to understand the laws governing his/her part of the universe and plot out the possible effects of his/her actions. Most road traffic legislation is based on this Newtonian idea of foreseeability. For example, a road traffic law in a typical Western country might specify how a motorist should adjust speed so as to be able to stop the vehicle before a crash occurs, and at the same time remaining aware of the circumstances that could influence speed selection (such as wet roads). Both the foreseeability of accidents and the awareness of circumstances are steeped in Newtonian Science. Both are also heavily susceptible to outcome bias. If something was not foreseen, then speed was surely too high. As a result, the system's user is always wrong [35].

Simply put, the opposing property from the perspective of Complexity Theory states that decision makers tend to make decisions that they think have the highest probability of producing a good outcome, based on their aims, limited focus and knowledge at a particular point in time [36]. 
Still, whether the good outcome occurs remain to be seen. Unfortunately, a system's complexity means that such actions might be locally adaptive, but globally maladaptive [37]. In other words, a seemingly logical decision may end up leading to a negative outcome. If so, this would suggests that an individual may not have the ability to direct a system away from disasters, meaning it is unlikely for heroes and villains to have a place in complex socio-technical systems.

\section{*.5.1 Case Study: Emergency Physician}

In their paper on medical diagnostic error, Croskerry and Nimmo [38] presented a case of a 28 years old female patient who was sent by her addiction treatment facility to a neighbouring emergency department. She claimed to be suffering from anxiety and chest pains over the past week, and was afraid that she might have a heart problem. The physician who was attending to her was sceptical of her claims as addicts from the treatment facility have been known to fake their injuries to obtain drugs [39]. Moreover, the patient left a bad impression on the physician as he had a busy schedule but was made to wait while she took a smoke break.

When the physician later reviewed the patient's electrocardiogram results and found no abnormalities, he diagnosed her with anxiety and discharged her [38]. After returning to the addiction treatment facility, the patient complained that her chest hurts, but her griping was not taken seriously as she had been medically cleared. She later passed away from a cardiac arrest caused by blood clots in her lungs, a result of her smoking habits and being on birth control pills.

In this scenario, the doctor made a decision which he believed would lead to the best possible outcome. He thought that the patient was just like the other addicts that came before her, feigning injuries to get their hands on drugs and hogging valuable resources in an emergency department that was already busy. As such, he quickly discharged her to avoid wasting resources on a fake patient. Unfortunately, his actions led to an unexpected negative outcome. This might indicate that an individual's ability is limited and as a consequence, it suggests that heroes and villains are unlikely to have a place in a complex socio-technical system as they effectively have little control over the outcome of their actions. 


\section{*.6 Time-Irreversibility}

The trajectory of a Newtonian system is not only towards the future, but also towards the past [18]. In principle, we can reverse the evolution of a system to reconstruct any earlier state that the system has gone through. Such assumptions give accident investigators the confidence that an accident can be reconstructed by starting with the outcome and then tracing its causal chain back into time. Knowledge about past events is assumed to be obtained via uncovering a pre-existing order. The only thing between an investigator and a good reconstruction are the limits on the accuracy of the representation of what happened. It follows that accuracy can be improved by "better" methods of investigation.

Complex systems, in contrast, are constantly adapting and evolving, and as such, it would be an uphill task for investigators to reconstruct the interactions leading up to an adverse outcome [18]. Additionally, any retrospective analysis of an accident would require the investigator to make a subjective judgement on which piece of information is important, and which is not, further skewing the reconstruction process $[18,40,41]$. It should also be noted that accident investigations in some domains (e.g. healthcare) can be problematic as it is more about what activities took place rather than physical evidence [41]. Hence, there is likely to be a greater reliance on the memories and perceptions of those involved. Yet contemporary research on memory strongly suggests that it is highly unreliable [42-44].

For example, Loftus and Palmer [43] presented participants with video footage of vehicular accidents before asking them questions about the footage. They found that when the verb smashed was used, participants' speed estimates tended to be higher. Furthermore, these participants were also more likely to report seeing broken glasses in the video footage, despite the fact that there was none.

Similarly, Itsukushima et al., [45] showed participants coloured slides portraying the daily activities of a woman before giving them additional information which they falsely claimed were the impressions and thoughts of past participants. Some participants received information that were consistent with the slides, while others were given fake information. They found that participants had 
a tendency to incorporate the bogus information into their memory, even though they were told that the information were simply the impression and thoughts of previous participants and therefore may not necessarily be true. In sum, retrospective analysis of an accident tends to be skewed, and the poor reliability of one's memory makes retrospective analyses even more unreliable.

\section{*.6.1 Case study: Eric Cropp}

In 2006, an infant passed away after being administered sodium chloride that was over twenty times stronger than the prescribed dosage [46]. Prosecutors held Eric Cropp, a pharmacist supervising the pharmacy technician who prepared the fatal solution, responsible for the accident and charged him with involuntary manslaughter. Eric Cropp ended up being given six months in jail, six months of home confinement, and three years of probation. Yet, should Eric Cropp really be blamed for this mishap?

According to information from newspapers and the Institute for Safe Medication Practices, the working conditions on the day of the accident were dreadful $[47,48]$. Some examples being: (a) a build-up of orders as the pharmacy computer system was not functioning earlier that day, (b) staffing shortage, (c) unable to perform normal work or take breaks, due to high workload, (d) the pharmacy technician who prepared the mixture was thought to be highly distracted as she was planning her wedding during working hours, and (e) being rushed to dispense the medication for the infant, even though it was not required for several hours.

Current research strongly indicates that stress and time pressure can adversely affect one's performance [49-52]. For example, Thompson et al. [52] gave 241 experienced nurses 50 vignettes depicting actual clinical scenarios and had the nurses assess the situation to decide if an intervention was necessary. Their study revealed that time pressure had a debilitating impact on nurses' performance, such that they were less likely to identify the need for an intervention and were also less likely to intervene.

Despite the presence of multiple detrimental factors that could have easily affected the performance of anyone, the prosecutors chose to hold Eric Cropp solely responsible for the accident 
[46]. In other words, Eric Cropp is the villain in this story. As mentioned above, the reconstruction process of an accident may be skewed as investigators make subjective judgements on which pieces of information are important, and which are not $[18,40,41]$. This seems to be what is happening here, with all the disadvantageous factors being deemed as unimportant pieces of information. The ignorance of these information and the labelling of Eric Cropp as a villain seems to suggest that heroes and villains do not objectively exist in complex systems. Rather, they seem to be constructs formed by investigators based on the information they collect and evaluate during the reconstruction process.

\section{*.7 Perpetual Incompleteness and Uncertainty of Knowledge}

Typical accident investigations seem to hold the view that an objective truth exists, and that knowledge about the truth can be obtained with the right investigation method [18]. Hence, the more information an investigator gathers, the more it leads to a better investigation, a better representation of "what happened". In other words, the true story where there is no gap between external events and their internal representation [53]. Those equipped with better methods, and those who enjoy greater "objectivity" (i.e. those who are free of biases, and will consider all the facts) are thought to be in a better position to construct such a true story.

However, such a notion is unlikely to be valid, at least for complex systems. Instead, it is believed that objective knowledge in complex systems cannot be obtained [18]. Every individual in complex systems will form their own set of knowledge as they each experience different inputs and outputs, with no objective mean of assessing who is in possession of the "truer" knowledge [18,54]. This is simply a result of the system being too complex, leading to each individual only being able to take into consideration a limited amount of inputs. Hence, their knowledge would always be incomplete and uncertain.

\section{*.7.1 Case Study: Mid Staffordshire}

In 2009, a scandal erupted at Stafford hospital when it was revealed by regulators that the hospital provided an appallingly low level of care [55]. Examples include patients being forced to soil 
their sheets and then being left in them, patients not being bathed for a long period of time, patients being given either the wrong food or none at all, and patients being given the wrong diagnoses [56]. The outrage was perhaps made worse by claims that hundreds of patients may have died due to these factors [57].

In response to this scandal, some have expressed a desire to find and punish the healthcare practitioners responsible [58,59]. Additionally, there have been reports of nurses losing their sense of compassion towards patients, further cementing the idea that the cause of the whole debacle comes from those at the front end $[60,61]$. In summary, there are those who advocate for the disciplining of healthcare practitioners based on the "input" of patient maltreatment and claims of nurses being callous.

The desire for retribution is understandable. However, evidence strongly indicates that these healthcare practitioners are working under incredibly harsh conditions. For one, staffing levels were cut to save money despite the high workload of the healthcare practitioners $[57,60,62]$. A BBC Radio interview with a midwife working in Stafford hospital revealed that she was chastised for caring due to time wasted [60]. Likewise, junior doctors were not properly supervised and were pressured to hastily meet and diagnose patients so that patients can be moved out from A\&E within four hours [57].

Moreover, people were prevented from speaking out as they would be labelled as a troublemaker or risk losing their job [60]. Julie Bailey spoke out against the Mid Staffordshire NHS Foundation Trust when she felt that her mother was receiving an atrocious level of care during her eight weeks at the Stafford hospital, and was bullied into leaving Stafford [63]. Examples of bullying behaviours against her include her car tires being slashed and her mother's grave being vandalised. Helene Donnelly, a nurse who once worked at Stafford hospital and later spoke out against it, recounted being threated and told to watch her back [64]. Lastly, a midwife reported feeling that there was a lack of support in the hospital for correcting bad behaviours, and that management would often belittle their suggestions for improvements [60]. 
Existing research in psychology strongly indicates that high workload and time pressure positively correlate with emotional exhaustion, one of the symptoms for burnout [65-67].

Additionally, emotional exhaustion correlates with depersonalisation, which is the development of distrust or unsympathetic attitudes toward others $[68,69]$. Research also suggests that holding the belief that one has little control over events in life makes one susceptible to burnout, a likely occurrence in Stafford hospital, given the hostile atmosphere towards those who step out of line [70]. Lastly, as mentioned earlier, psychological studies suggest that stress and time pressure can have a detrimental effect on one's performance [49-52].

Taken together, it would suggest that the "input" of high workload and time pressure could have caused practitioners to experience emotional exhaustion, which led to them depersonalising their patients and thus producing the "output" of no compassion. Likewise, the "input" of having to quickly assess patients under pressure and without guidance might be the reason for the "output" of misdiagnoses.

To conclude, both the advocates for punishment and the healthcare practitioners at the hospital have formed their own ideas based on their different inputs and outputs. Any attempts to objectively determine who is right would be a difficult task (if not impossible). It is an undeniable fact that the healthcare practitioners at Stafford hospital have caused both suffering and a loss of dignity to patients. Therefore, the calls for them to be punished seem like a reasonable response. Yet, it hardly seems fair to label the practitioners as the "villains", given that the system was rigged against them.

\section{*.8 What Does This Mean for Heroes and Villains in Complex Socio-Technical Systems?}

To recap, the case of Florence Nightingale exerting great influence over the healthcare systems in various countries seems to strongly indicate the possibility for heroes and villains to exist in complex socio-technical systems. In contrast, the case of the emergency physician suggests that heroes and villains are unlikely to exist in such systems as they have little control over the outcome of their actions. 
Similarly, the case with Eric Cropp can be said to demonstrate that villains (and therefore heroes) are simply social constructs formed by investigators based on their subjective judgements. Lastly, the case with Mid Staffordshire suggests that an objective set of truth does not always exist. Instead, each individual will form their own set of knowledge grounded in their own experiences and one man's hero might be another man's villain. After all, while the actions of Julie Bailey and Helene Donnelly are arguably heroic, they have been vilified by others $[63,64]$.

Taking the above into consideration, this can mean that heroes and villains can exist in complex socio-technical systems. However, to call them as such might be highly inappropriate. As argued above, the healthcare practitioners in each case were normal people working to the best of their ability, making decisions that appeared rational to them at that point in time, and/or managing various external factors that were working against them. While some were successful in their endeavours (i.e. Florence Nightingale), others were not as the odds were stacked against them. Calling these people villains simply because they were unable to overcome systemic handicaps or because they do not fit our subjective judgments seems unfair.

Interestingly, Strachey [71] suggested that perhaps Florence Nightingale's achievements were possible partly due to systemic factors being in her favour. He suggested that the timing of the Crimean War was perfect for Florence Nightingale, since she would have been too inexperienced if the war had begun a few years earlier. Conversely, if the war started a few years later, Florence Nightingale might have been preoccupied with other works and may perhaps be too old to handle the demands that would have been imposed on her.

Furthermore, Florence Nightingale was born into a well-connected political family, which likely gave her an edge in some areas $[24,25,71]$. For one, then Secretary of State at War Sidney Herbert was a personal friend of Florence Nightingale. The decision to choose Florence Nightingale as the one to lead female nurses to the front line was said to be a result of her offering her services, and Sidney Herbert's belief that she was the right woman for the job based on his knowledge of her in a personal capacity. Moreover, as mentioned above, these connections also gave her some influence which she used to push for improvements in hospitals on the front line. Lastly, Florence Nightingale's 
fame from the Crimean War resulted in the establishment of the Nightingale Fund that was used to found the Nightingale Training School for nurses, which had a deep impact on the nursing domain [27].

In summary, heroes and villains can potentially exist in complex socio-technical systems. However, it would be illogical to call them as such. A myriad of external factors are at play, working for and/or against every individual in the system. To hail some as heroes simply because the odds were in their favour, while vilifying others because the odds were against them seems both absurd and unfair.

\section{*.9 Conclusion}

When success or failures are seen as complex, emergent phenomena, there is no longer an obvious relationship between the behaviour of components in the system (or their malfunctioning, e.g. "human errors" or their spectacular success, e.g. "heroes" or "heroic recoveries") and system-level outcomes [18]. Instead, system-level behaviours emerge from the multitude of relationships and interactions within the system. Investigations that embrace the complexity produced by such relationships and interactions, then, might stop looking for the "causes" of failure or success. Instead, such investigations gather multiple narratives from different perspectives, which give partially overlapping and partially contradictory accounts of how emergent outcomes arise. The complexity perspective dispenses with the notion that there are easy answers to events within a complex system, answers that supposedly can be achieved by those with the best method or most objective investigative viewpoint.

Perhaps the question about the existence of heroes or villains in a complex system is unanswerable. Reconstructing events in a complex system is impossible, primarily as a result of the characteristics of complexity [18]. The complex system that is subjected to an investigation after an incident is not the same system that produced the incident. It will have changed, partly because of the incident, partly because of the passage of time, and the nature of complexity. Psychological characteristics of retrospective investigations make it so too. Take, for instance, the idea that a 
sequence of events or chain of causes precede an accident. Who makes the selection of the "events" or "causes" and on what basis? And why only a single chain? The act of separating factors deemed important from unimportant ones is an act of imagination, of construction, of the creation of a story, not the reconstruction of a story that was already there, waiting to be uncovered. Such actions of imagination bring with it a bunch of selection mechanisms and criteria into the supposed "re"construction. There is no objective way of doing this as the investigator's own background, preferences, experiences, biases, beliefs, and purposes all influence the investigation.

Not surprisingly, Complexity Theory suggests that the observer is not just a passive consumer, but the active creator of the observed [72]. In complexity, there is no method to decide which narrative is correct [18]. However, some narratives will deliver more interesting results than others, depending on the goals of the audience. The selection of "causes" (or "events" or "contributory factors") is always an act of construction by the investigators. If the sheer notion of heroes and villains is part of their narrative fore-structure, for example because of institutional or cultural needs, then the complex system, and the interactions between components and events in it, may well be construed so that heroes or villains become key players in the story. 


\section{References}

1. Haq H. How human error can cause a plane crash. BBC Travel [Internet]. UK; 2013; Available from: http://www.bbc.com/travel/story/20130521-how-human-error-can-cause-a-plane-crash

2. Holden RJ. People or systems? to blame is human. the fix is to engineer. Prof. Saf. 2009;54:34-41.

3. Levitt P. When medical errors kill: american hospitals have embraced a systems solution that doesn't solve the problem. Los Angeles Times [Internet]. Los Angeles; 2014; Available from: http://articles.latimes.com/2014/mar/15/opinion/la-oe-levitt-doctors-hospital-errors-20140316

4. Murty M. MH370: sack those who 'slept on the job'. The Rakyat Post [Internet]. Kuala Lumpur; 2014; Available from: http://www.therakyatpost.com/news/2014/06/18/mh370-sack-slept-job/

5. National Transportation Safety Board. Lack of consideration for human factors led to in-flight breakup of SpaceShipTwo. 2015; Available from: http://www.ntsb.gov/news/pressreleases/Pages/PR20150728.aspx

6. National Transportation Safety Board. Most wanted list of transportation safety improvements. Washington, D.C.; 2015.

7. Topham G. 'Railway accidents happen because someone makes a mistake'. The Guardian [Internet]. London; 2013; Available from: http://www.theguardian.com/uk-news/2013/jul/25/railwayaccidents-human-error-warning-systems

8. Alper SJ, Karsh B-T. A systematic review of safety violations in industry. Accid. Anal. Prev. 2009;41:739-54.

9. de Brito G. Study of the use of Airbus flight-deck procedures and perspectives for operational documentation. Int. Conf. Hum. Comput. Interact. Aeronaut. 1998. p. 195-201.

10. de Saint Maurice G, Auroy Y, Vincent C, Amalberti R. The natural lifespan of a safety policy: violations and system migration in anaesthesia. Qual. Saf. Health Care. 2010;19:327-31. 
11. Vicente KJ. Preface. Cognitive work analysis: towards safe, productive, and healthy computerbased work. New Jersey: Lawrence Erlbaum Associates; 1999. p. xiii - xix.

12. Xiao-qian C, Hui-tao L. Gray relational analysis on airline employees' pay satisfaction and violations. International Conference on Management Science \& Engineering (20th). 2013. p. 288-93.

13. Dekker S. Safety differently: human factors for a new era. Florida: CRC Press; 2014.

14. Hollnagel E. Safety-I and safety-II : the past and future of safety management. Farnham: Ashgate Publishing Ltd; 2014.

15. Reason J. The human contribution: unsafe acts, accidents and heroic recoveries. Surrey: Ashgate Publishing Limited; 2008.

16. Clarke DM. The human contribution: unsafe acts, accidents and heroic recoveries. J. Risk Res. 2010;14:144-5.

17. Leveson NG. System safety engineering: back to the future. Boston: MIT Aeronautics and Astronautics; 2002.

18. Dekker S, Cilliers P, Hofmeyr J-H. The complexity of failure: implications of complexity theory for safety investigations. Saf. Sci. 2011;49:939-45.

19. Dekker S. Drift into failure: from hunting broken components to understanding complex systems. Surrey: Ashgate Publishing Limited; 2011.

20. Rochlin GI, La Porte TR, Roberts KH. The self-designing high-reliability organisation: aircraft carrier flight operations at sea. Nav. War Coll. Rev. 1998;51:97-113.

21. Arnstein MG. Florence Nightingale's influence on nursing. Bull. N. Y. Acad. Med. 1956;32:5406.

22. Horsley K. Florence Nightingale. J. Mil. Veterans Health. 2010;18:4-5. 
23. Winkelstein Jr W. Florence Nightingale: founder of modern nursing and hospital epidemiology. Epidemiology. 2009;20:311.

24. Baly ME, Matthew HCG. Nightingale, Florence. In: Goldman L, editor. Oxford dictionary of national biography. [Internet]. Oxford University Press; 2011. Available from: http://www.oxforddnb.com/view/article/35241?docPos=2

25. Helmstadter C. Navigating the political straits in the Crimean War. In: Nelson S, Rafferty AM, editors. Notes on Nightingale: the influence and legacy of a nursing icon. New York: Cornell University Press; 2010. p. 28-54.

26. Smith CW. Florence Nightingale, 1820-1910. London: Constable and Company Ltd; 1950.

27. Godden J. The dream of nursing the empire. In: Nelson S, Rafferty AM, editors. Notes on Nightingale: the influence and legacy of a nursing icon. New York: Cornell University Press; 2010. p. $55-75$.

28. Godden J. Lucy Osburn, a lady displaced. New South Wales: Sydney University Press; 2006.

29. Fox JC. Mass. General exhibit honors a pioneer of nursing education. Boston Globe [Internet]. Massachusetts; 2014; Available from: https://www.bostonglobe.com/lifestyle/healthwellness/2014/04/27/mass-general-portrait-exhibit-honor-pioneer-nursingeducation/zwKAMEeWXycyXwToeBp03I/story.html

30. Snodgrass ME. Historical encyclopedia of nursing. California: ABC-CLIO; 1999.

31. Cook ET. The life of Florence Nightingale vol. 2 of 2. London: Macmillan and Co., Limited; 1913.

32. Thomson D. Workhouse to nursing home: residential care of elderly people in England since 1840. Ageing Soc. 1983;3:43-69. 
33. Magnello ME. The passionate statistician. In: Nelson S, Rafferty AM, editors. Notes on Nightingale: the influence and legacy of a nursing icon. New York: Cornell University Press; 2010. p. $115-29$.

34. Global Aviation Information Network. Roadmap to a just culture: enhancing the safety environment. Global Aviation Information Network Working Group E; 2004 p. 46.

35. Tingvall C, Lie A. The concept of responsibility in road traffic (Ansvarsbegreppet i vägtrafiken). Transp. Linköping Swed. 2010;

36. Woods DD, Dekker S, Cook R, Johannesen L, Sarter N. Behind human error. 2nd ed. Surrey: Ashgate Publishing Ltd; 2010.

37. Dekker S, Pruchnicki S. Drifting into failure: theorising the dynamics of disaster incubation. Theor. Issues Ergon. Sci. 2014;15:534-44.

38. Croskerry P, Nimmo GR. Better clinical decision making and reducing diagnostic error. J. R. Coll. Physicians Edinb. 2011;41:155-62.

39. Anderssen E. When doctors make bad calls. The Globe and Mail [Internet]. Toronto; 2012; Available from: http://www.theglobeandmail.com/life/health-and-fitness/when-doctors-make-badcalls/article549084/?page $=$ all

40. Lundberg J, Rollenhagen C, Hollnagel E. What-you-look-for-is-what-you-find - the consequences of underlying accident models in eight accident investigation manuals. Saf. Sci. 2009;47:1297-311.

41. Nemeth C, Cook RI, Patterson E, Donchin Y, Rogers M, Ebright P. Afterwords: the quality of medical accident investigations and analyses. SAGE Publications; 2004. p. 2084-8.

42. Lindsay DS. Misleading suggestions can impair eyewitnesses' ability to remember event details. J. Exp. Psychol. Learn. Mem. Cogn. 1990;16:1077-83. 
43. Loftus EF, Palmer JC. Reconstruction of automobile destruction: an example of the interaction between language and memory. J. Verbal Learn. Verbal Behav. 1974;13:585-9.

44. Ramirez S, Liu X, Lin P-A, Suh J, Pignatelli M, Redondo RL, et al. Creating a false memory in the hippocampus. Science. 2013;341:387-91.

45. Itsukushima Y, Nishi M, Maruyama M, Takahashi M. The effect of presentation medium of postevent information: impact of co-witness information. Appl. Cogn. Psychol. 2006;20:575-81.

46. Carrabine N. Ex-pharmacist sentenced to jail in death of Mentor girl. The News-Herald. [Internet]. Ohio; 2009; Available from: http://www.news-herald.com/general-news/20090814/ex-pharmacistsentenced-to-jail-in-death-of-mentor-girl

47. Institute for Safe Medication Practices. Ohio government plays whack-a-mole with pharmacist. ISMP Newsletters. [Internet]. 2009; Available from:

https://www.ismp.org/newsletters/acutecare/articles/20090827.asp

48. McCoy K, Brady E. Rx for errors: drug error killed their little girl. USA TODAY [Internet]. Virginia; 2009; Available from: http://usatoday30.usatoday.com/money/industries/health/2008-02-24emily_N.htm

49. Gimmig D, Huguet P, Caverni J-P, Cury F. Choking under pressure and working memory capacity: when performance pressure reduces fluid intelligence. Psychon. Bull. Rev. 2006;13:100510.

50. Kellogg JS, Hopko DR, Ashcraft MH. The effects of time pressure on arithmetic performance. J. Anxiety Disord. 1999;13:591-600.

51. Slobounov SM, Fukada K, Simon R, Rearick M, Ray W. Neurophysiological and behavioural indices of time pressure effects on visuomotor task performance. Cogn. Brain Res. 2000;9:287-98. 
52. Thompson C, Dalgleish L, Bucknall T, Estabrooks C, Hutchinson AM, Fraser K, et al. The effects of time pressure and experience on nurses' risk assessment decisions: a signal detection analysis. Nurs. Res. 2008;57:302-11.

53. Heylighen F. Causality as distinction conservation. a theory of predictability, reversibility, and time order. Cybern. Syst. Int. J. 1989;20:361-84.

54. Heylighen F, Cilliers P, Gershenson C. Complexity and philosophy. In: Bogg J, Geyer R, editors. Complexity, science and society. Oxford: Radcliffe Publishing; 2007.

55. Telegraph Reporters. Mid Staffordshire Trust inquiry: how the care scandal unfolded. The Telegraph [Internet]. London; 2013; Available from: http://www.telegraph.co.uk/news/health/news/9851763/Mid-Staffordshire-Trust-inquiry-how-thecare-scandal-unfolded.html

56. Francis R. Independent inquiry into care provided by Mid Staffordshire NHS Foundation Trust January 2005 - March 2009 volume I. London: London: The Stationery Office; 2010 p. 452.

57. Healthcare Commission. Investigation into Mid Staffordshire NHS Foundation Trust. London: Healthcare Commission; 2009.

58. Pearson A. Forget hacking hacks, let's jail some callous Mid Staffs NHS staff. The Telegraph [Internet]. London; 2013; Available from:

http://www.telegraph.co.uk/news/health/news/9867843/Forget-hacking-hacks-lets-jail-some-callousMid-Staffs-NHS-staff.html

59. Triggle N. Stafford Hospital: hiding mistakes 'should be criminal offence'. BBC News [Internet]. London; 2013; Available from: http://www.bbc.co.uk/news/health-21341766

60. BBC News. NHS nurses 'penalised for caring' [Internet]. 2013. Available from: http://www.bbc.com/news/uk-21348797 
61. Campbell D. Mid Staffs hospital scandal: the essential guide. The Guardian [Internet]. London; 2013; Available from: http://www.theguardian.com/society/2013/feb/06/mid-staffs-hospital-scandalguide

62. Francis R. Report of the Mid Staffordshire NHS Foundation Trust public inquiry: executive summary. London: London: The Stationery Office; 2013.

63. Adams T. Mid Staffs whistleblower Julie Bailey: 'I don't go out here on my own any more'. The Guardian [Internet]. London; 2013; Available from:

http://www.theguardian.com/society/2013/oct/27/julie-bailey-mid-staffordshire-nhs-whistleblower

64. BBC News. Stafford Hospital inquiry: final witness's tears at bullying. BBC News [Internet]. London; 2011; Available from: http://www.bbc.com/news/uk-england-stoke-staffordshire-15210964

65. Crawford ER, LePine JA, Rich BL. Linking job demands and resources to employee engagement and burnout: a theoretical extension and meta-analytic test. J. Appl. Psychol. 2010;95:834-48.

66. Janssen PPM, De Jonge J, Bakker AB. Specific determinants of intrinsic work motivation, burnout and turnover intentions: a study among nurses. J. Adv. Nurs. 1999;29:1360-9.

67. Maslach C, Jackson SE. The measurement of experienced burnout. J. Occup. Behav. 1981;2:99113.

68. Glasberg A-L, Eriksson S, Norberg A. Burnout and 'stress of conscience' among healthcare personnel. J. Adv. Nurs. 2007;57:392-403.

69. Laschinger HKS, Leiter MP. The impact of nursing work environments on patient safety outcomes: the mediating role of burnout engagement. J. Nurs. Adm. 2006;36:259-67.

70. Schmitz N, Neumann W, Oppermann R. Stress, burnout and locus of control in German nurses. Int. J. Nurs. Stud. 2000;37:95-9.

71. Strachey L. Eminent Victorians. Middlesex: Penguin Books; 1977. 
72. Wallerstein I. Open the social sciences: report of the Gulbenkian Commission on the restructuring of the social sciences. California: Stanford University Press; 1997. 